$\mathrm{CI}[1.69-21.77])$. The same finding was observed between high concentrations of HDLc and the prevalence of VF adjusted in the same variables $(p=0.006, O R$ : 197.01, 95\% Cl [4.64-8363.51]).

Conclusion: Although there was no relation between lipid plasma levels and BMD in our population. There was a significant association between high concentrations of TC, HDLc and the prevalence of VF.

Disclosure of Interests: None declared

DOI: 10.1136/annrheumdis-2020-eular.4715

\begin{tabular}{|l|l}
\hline FRI0069 & EFFECTS OF ADALIMUMAB ADDED TO TREAT-TO- \\
TARGET STRATEGY WITH METHOTREXATE AND \\
INTRA-ARTICULAR TRIAMCINOLONE ON LIPIDS \\
IN EARLY- AND TREATMENT NAÏVE RHEUMATOID \\
PATIENTS: SECONDARY ANALYSES FROM THE \\
MULTICENTER DOUBLE-BLIND, RANDOMIZED, \\
PLACEBO-CONTROLLED OPERA TRIAL
\end{tabular}

D. Masic ${ }^{1}$, K. Stengaard-Pedersen ${ }^{2}$, B. B. Løgstrup ${ }^{3}$, K. Hørslev-Petersen ${ }^{4}$, M. L. Hetland ${ }^{5}$, P. Junker ${ }^{1}$, M. Ǿstergaard ${ }^{5}$, C. Ammitzbøl ${ }^{2}$, S. Möller 6 , R. Christensen ${ }^{1}$, T. Ellingsen ${ }^{1}{ }^{1} S D U$, Research Unit of Rheumatology, Odense, Denmark; ${ }^{2}$ Aarhus University, Dep. of Rheumatology, Aarhus, Denmark; ${ }^{3}$ Aarhus University, Dep. of Cardiology, Aarhus, Denmark; ${ }^{4} S D U$, King Christian 10th Hospital for Rheumatic Diseases, Sønderborg, Denmark; ${ }^{5}$ Rigshospitalet, COPECARE \& DANBIO, Glostrup, Denmark; ${ }^{6}$ SDU, OPEN, Odense, Denmark

Background: Systemic inflammation in rheumatoid arthritis (RA) is associated with reduced serum lipid levels (LL) and treatment with disease modifying antirheumatic drugs has been associated with increased serum LL [1]. It is unclear whether the changes in serum LL reported in association with adalimumab (ADA) treatment are due to suppressed inflammation or the ADA treatment perse.

Objectives: The primary objective was to compare the effect of ADA + methotrexate (MTX) to placebo (PBO) + MTX on changes in low density lipoprotein cholesterol (LDL-C) from baseline to month 12 in patients with early- and treatment naïve RA. Secondary objectives were to compare the treatment groups on changes in total cholesterol (TC), high density lipoprotein cholesterol (HDL-C), triglycerides, very low density lipoprotein cholesterol (VLDL-C) and non-HDL-C (=TC - HDL-C).

Methods: We present secondary analyses from the OPERA trial, which was an investigator-initiated, multicenter double-blind, placebo-controlled, treatto-target trial of 180 early and treatment naïve RA patients, who were randomized (1:1) to oral MTX $20 \mathrm{mg}$ once a week in combination with either PBO or ADA $40 \mathrm{mg}$ SC EOW [2]. Any swollen joint was injected with triamcinolone hexacetonide. Lipid profiles of each patient were assessed at baseline and 12 months. All randomized patients with available LDL-C at baseline were included in Intention To Treat (ITT) analysis. Sensitivity analyses were performed on the Per Protocol (PP) and the ITT population with baseline observations carried forward (BOCF). All analyses were based on repeated measurements using mixed linear models.

Results: In total, 174 patients (97\% of the original OPERA trial population) were included in ITT analysis (ADA $n=86$; $P B O n=88$ ) and 156 patients (ADA $\mathrm{n}=78$; PBO $\mathrm{n}=78$ ) completed the study with LDL-C measurements at both baseline and 12 months (PP). At baseline mean LDL-C was $2.9 \mathrm{mmol} / \mathrm{L}$ (SD $0.9)$ with $63(36.2 \%)$ patients having an LDL-C above $3.0 \mathrm{mmol} / \mathrm{L}$. There was

Table. Change in primary and secondary outcomes in the ITT analysis

\begin{tabular}{|c|c|c|c|c|c|c|c|}
\hline & \multicolumn{2}{|c|}{$\begin{array}{l}\text { Adalimumab } \\
\qquad(\mathrm{n}=86)\end{array}$} & \multicolumn{2}{|c|}{$\begin{array}{c}\text { Placebo } \\
(n=88)\end{array}$} & \multirow{2}{*}{$\begin{array}{c}\text { Difference } \\
\text { between } \\
\text { means }\end{array}$} & \multirow[b]{2}{*}{$(95 \% \mathrm{Cl})$} & \multirow{2}{*}{$\begin{array}{c}P \\
\text { value }\end{array}$} \\
\hline & Mean & SE & Mean & SE & & & \\
\hline 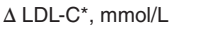 & 0.26 & 0.08 & 0.07 & 0.08 & 0.18 & $(-0.05 ; 0.42)$ & 0.12 \\
\hline$\Delta \mathrm{TC}, \mathrm{mmol} / \mathrm{L}$ & 0.49 & 0.10 & 0.22 & 0.10 & 0.27 & $\begin{array}{r}(-0.002 \\
0.54)\end{array}$ & 0.052 \\
\hline$\Delta \mathrm{HDL}-\mathrm{C}, \mathrm{mmol} / \mathrm{L}$ & 0.27 & 0.04 & 0.23 & 0.04 & 0.05 & $(-0.06 ; 0.15)$ & 0.38 \\
\hline$\Delta \mathrm{TG}, \mathrm{mmol} / \mathrm{L}$ & -0.07 & 0.07 & -0.18 & 0.07 & 0.11 & $(-0.08 ; 0.29)$ & 0.25 \\
\hline$\Delta \mathrm{VLDL}-\mathrm{C}, \mathrm{mmol} / \mathrm{L}$ & -0.03 & 0.03 & -0.07 & 0.03 & 0.03 & $(-0.05 ; 0.12)$ & 0.43 \\
\hline$\Delta$ non-HDL-C, mmol/L & 0.22 & 0.09 & 0.00 & 0.09 & 0.22 & $(-0.02 ; 0.46)$ & 0.07 \\
\hline
\end{tabular}

$\triangle L D L-C$, Sensitivity Analyses

\begin{tabular}{|c|c|c|c|c|c|c|c|}
\hline Per Protocol & 0.27 & 0.08 & 0.08 & 0.08 & 0.19 & $(-0.04 ; 0.42)$ & 0.11 \\
\hline $\mathrm{BOCF}$ & 0.26 & 0.08 & 0.08 & 0.08 & 0.18 & $(-0.03 ; 0.40)$ & 0.10 \\
\hline
\end{tabular}

$\Delta=12$ months - baseline. *Primary outcome. ITT: Intention To Treat. BOCF: Baseline Observation Carried Forward. LDL-C: low-density lipoprotein cholesterol. TC: total cholesterol. HDL-C: high-density lipoprotein cholesterol. TG: triglycerides. VLDL-C: very-low-density lipoprotein cholesterol. non-HDL-C $=\mathrm{TC}-\mathrm{HDL}-\mathrm{C}$. no significant difference in LDL-C change between ADA+MTX and PBO+MTX groups after 12 months. A nearly statistically significant between-group difference in TC change was found. Other changes in LL were comparable across the two groups. Results in ITT, PP and ITT with BOCF populations were similar.

Conclusion: In early RA patients treated to target with methotrexate and intra-articular triamcinolone, 12 months with the addition of adalimumab did not affect lipid levels.

References:

[1] England BR et al., Bmj 2018;361:k1036

[2] Hørslev-Petersen K et al., Ann Rheum Dis 2014;73:654-61

Disclosure of Interests: Dzenan Masic: None declared, Kristian Stengaard-Pedersen: None declared, Brian Bridal Løgstrup: None declared, Kim Hørslev-Petersen Grant/research support from: Pfizer (Travel expences), Merete L. Hetland Grant/research support from: BMS, MSD, AbbVie, Roche, Novartis, Biogen and Pfizer, Consultant of: Eli Lilly, Speakers bureau: Orion Pharma, Biogen, Pfizer, CellTrion, Merck and Samsung Bioepis, Peter Junker: None declared, Mikkel Ǿstergaard Grant/research support from: AbbVie Bristol-Myers Squibb, Celgene, Merck, and Novartis, Consultant of: AbbVie, Bristol-Myers Squibb, Boehringer Ingelheim, Celgene, Eli Lilly, Hospira, Jans sen, Merck, Novartis, Novo Nordisk, Orion, Pfizer, Regeneron, Roche, Sandoz, Sanofi, and UCB, Speakers bureau: AbbVie, Bristol-Myers Squibb, Boehringer Ingelheim, Celgene, Eli Lilly, Hospira, Janssen, Merck, Novartis, Novo Nordisk Orion, Pfizer, Regeneron, Roche, Sandoz, Sanofi, and UCB, Christian Ammitz bøl: None declared, Sören Möller: None declared, Robin Christensen: None declared, Torkell Ellingsen: None declared DOI: 10.1136/annrheumdis-2020-eular.739

\section{FRI0070 1 PREGNANCY AND OFFSPRING OUTCOME IN RA FEMALE PATIENTS- A BOW BETWEEN CENTURIES}

M. Micu ${ }^{1}$, A. Micu ${ }^{2}{ }^{1}$ Rehabilitation Clinical Hospital Cluj-Napoca,

Rheumatology Division, Cluj-Napoca, Romania; ${ }^{2}$ Iuliu Hațieganu" University of Medicine and Pharmacy, Cluj-Napoca, Romania

Background: Clinical and preclinical rheumatoid arthritis (RA) may negatively impact several pregnancy and offspring outcome parameters [1,2].

Objectives: Assessing pregnancy and offspring outcome in RA patients and controls.

Methods: RA pregnant patients (G1) were prospectively recruited. Demographic data, disease activity scores, immunology and obstetric/offspring outcome parameters were recorded. The same parameters were retrospectively collected (interview) in RA patients who delivered children before RA onset (G2) and in healthy subjects $(C)$. Ethical committee approval for the study was obtained and all participants signed informed consents.

Results: Table 1 presents demographic and disease related data. Table 2 shows the outcome parameters in the 3 groups. G1 delivered babies between the years 2008-2019. CsDMARDs were stopped by the majority of patients in the $1^{\text {st }}$ trimester of pregnancy; 2 patients continued low dose corticosteroids throughout pregnancy (Fig 1). G2 and C delivered the babies between the years 1963 and 2000.

Table 1.

\begin{tabular}{lccc}
\hline Parameter & G1 & G2 & C \\
\hline Subjects^ $^{\wedge}$ & 22 & 27 & 36 \\
Disease duration $(\mathrm{y} \pm \mathrm{SD})$ & $5.92 \pm 6.14$ & - & - \\
Disease activity & & & - \\
T1-R/LDA/HDA^ & $9 / 15 / 5$ & - & \\
T2- R/LDA/HDA^ & $15 / 6 / 8$ & & - \\
T3- R/LDA/HDA^ & $18 / 6 / 5$ & 92.59 & - \\
RF + (\%) & 86.36 & 62.96 & 5 \\
ACPA + (\%) & 36.36 & 3 & 1 \\
Contraception^ & 0 & 1 & \\
Fertility treatment^ & 1 & & \\
\hline
\end{tabular}

^- number, y- years, SD- standard deviation, R-remission, LDA-low disease activity, HDA-high disease activity, ${ }^{*}$ DAS 283 variables, T-trimester

Overall, RA pregnant patients were older at conception, had a lower number of pregnancies/deliveries and a higher rate of spontaneous abortions and ' $\mathrm{C}$ ' sections compared to $\mathrm{G} 2$ and $\mathrm{C}$. Time to pregnancy (TTP) was increased in G1 when compared to $\mathrm{G} 2$ and $\mathrm{C}$. Both $\mathrm{G} 1$ and $\mathrm{G} 2$ newborns were smaller for their gestational age versus $C$, the majority of them still being in the normal range. All these aforementioned parameters showed statistical significance. Number of premature deliveries and pregnancy/offspring pathology events showed a low frequency and no difference was identified between groups when comparing them 